Association for Information Systems

AIS Electronic Library (AISeL)

PACIS 2012 Proceedings

Pacific Asia Conference on Information Systems

(PACIS)

$7-15-2012$

\title{
Creating And Sharing Knowledge Through A Corporate Social Networking Site: The Impact Of Employees' Perceptions On Effectiveness
}

Julio Figueroa

Victoria University of Wellington, Wellington, New Zealand, figuerjuli@myvuw.ac.nz

Jocelyn Cranefield

Victoria University of Wellington, Wellington, New Zealand, jocelyn.cranefield@vuw.ac.nz

Follow this and additional works at: http://aisel.aisnet.org/pacis2012

\section{Recommended Citation}

Figueroa, Julio and Cranefield, Jocelyn, "Creating And Sharing Knowledge Through A Corporate Social Networking Site: The Impact Of Employees' Perceptions On Effectiveness" (2012). PACIS 2012 Proceedings. 172.

http://aisel.aisnet.org/pacis2012/172

This material is brought to you by the Pacific Asia Conference on Information Systems (PACIS) at AIS Electronic Library (AISeL). It has been accepted for inclusion in PACIS 2012 Proceedings by an authorized administrator of AIS Electronic Library (AISeL). For more information, please contact elibrary@aisnet.org. 


\title{
CREATING AND SHARING KNOWLEDGE THROUGH A CORPORATE SOCIAL NETWORKING SITE: THE IMPACT OF EMPLOYEES' PERCEPTIONS ON EFFECTIVENESS
}

Julio Figueroa, Victoria University of Wellington, Wellington, New Zealand, figuerjuli@myvuw.ac.nz

Jocelyn Cranefield, Victoria University of Wellington, Wellington, New Zealand, jocelyn.cranefield@vuw.ac.nz

\begin{abstract}
There have been various claims that enterprise social networking sites (ESN) might improve business effectiveness and performance. Nevertheless, many of the initiatives supported by ESNs have failed. This paper argues that divergent perceptions about ESNs across the different levels of the organization may explain failures in ESNs' design and implementation. Using an extended version of the Technological Frames of Reference framework (Orlikowski \& Gash, 1994), this paper reports on a study that analyzed employee's perceptions about an ESN within a software engineering firm. It was found that significant divergent perceptions in the organization led to a social order that discouraged employees to create and share knowledge through the ESN. This paper highlights the importance of aligning top management perceptions about the ESN with its actual scope. It also highlights the relevance of aligning perceptions about the ESN across the different levels of the organization. This paper proposes extending the original Technological Frames of Reference framework in order to better understand people's perceptions about technologies that support knowledge management systems. It also proposes an explanatory model for understanding how people's perceptions about a corporate social networking site impact on its usage.
\end{abstract}

Keywords: enterprise social networking, technological frames, social media, enterprise 2.0, group work, knowledge markets 
Various authors have suggested that corporate social networking tools may improve business effectiveness and performance (DiMicco, et al., 2008; Gartner, 2010; Miller, Marks, \& DeCoulode, 2011; Steinfield, DiMicco, Ellison, \& Lampe, 2009). Moreover, it seems likely that organizations may start receiving significant pressure for adopting these kinds of tools. For example, the younger generation finds social networking sites natural and studies suggest that they expect this technology to be available in their workplace (Gartner, 2010; Levy, 2009). Furthermore, technologist research specialist Gartner has predicted that by 2014 social networking services will replace e-mail as the primary vehicle for interpersonal communications for twenty percent of business users (Gartner, 2010). Nevertheless, there is no consensus about the actual value of social networking sites for organizations. On the one hand, several authors claim that there is no evidence that these tools are useful for business performance (Baltatzis, Ormrod, \& Grainger, 2009; Miller, et al., 2011), while Miller et al. (2011) state that most early adopters have not demonstrated business performance impacts. On the other hand, some authors have found potential benefits (Riemer, Richter, \& Seltsikas, 2010; Steinfield, et al., 2009). While there are many possible reasons for this lack of consensus, it can be seen as unsurprising when is recognised that the success of an information systems (IS) is bound up with people's perceptions: IS success is achieved "when an IS is perceived to be successful by the stakeholders and other observers" (Myers, 1995, p. 65). Orlikowski and Gash (1994) have previously highlighted the important role that frames of reference play in shaping the views and responses of diverse stakeholders' views about technology. Using the Orlikowski and Gash's (1994) Technological Frames of Reference (TFR) framework we outline how the perceptions of different stakeholders within a software engineering firm negatively affected the use of an enterprise social networking site as part of a knowledge management system.

This paper begins with an overview of research on social networking sites and issues related to the management of knowledge in software engineering companies. Following this we outline the methodology used for our study and then report on the study's findings. The paper concludes with a discussion of the implications of these findings for future research and practice.

\section{LITERATURE REVIEW}

\subsection{Knowledge Management Systems and Knowledge Management Strategy}

In this century, economic competition is often related to the quality of organizational knowledge and the way it is applied in doing business (Davidson \& Voss, 2002). In the mid 1980s, individuals and organizations started appreciating the increasingly important role of knowledge, and hence the need for its management (Wiig, 1997). As a result, many organizations design organizational processes for facilitating the codification, collection, integration and dissemination of organizational knowledge. The overarching set of processes is referred to as Knowledge Management Systems (KMS) (Alavi \& Leidner, 1999). KMSs should not been confounded with technologies as they may or may not be supported by IT (Alavi \& Leidner, 2001; Davidson \& Voss, 2002; Mohamed, Stankosky, \& Murray, 2006). Even when IT plays a in KMSs, it is no more important than other aspects of KM: leadership, organization and learning (Davidson \& Voss, 2002; Mohamed, et al., 2006).

Depending on the way that an organization serves its clients, the economics of its business and the people it hires, it has been suggested that organizations should choose between two broad KM strategies: the personalization and the codification strategy (Greiner, Bohmann, \& Krcmar, 2007; Morten, Nohria, \& Tierney, 1999). The codification strategy focuses on codifying and storing explicit knowledge in databases, making knowledge independent from the originator. On the other hand, the personalization strategy recognizes that knowledge is closely tied to the person who developed it and thereby knowledge is shared mainly through the socialization mechanism, which is the mechanism that transfers tacit knowledge through sharing experiences or mentoring relationships among others (Nonaka \& Takeuchi, 1995). The codification strategy typically involves using IT for databases and information repositories (Greiner, et al., 2007; Morten, et al., 1999), whereas the personalization 
strategy uses IT for helping people to communicate knowledge, not to store it. KMSs that support the personalization approach should therefore encourage socialization processes. Some Web 2.0 technologies can support these KMSs, for example, social networking tools, which are the focus of this research (Michailova \& Gupta, 2005). In the following section we consider the characteristics of knowledge in the software engineering industry, and the implications of these for the selection of KM strategy and systems.

\subsection{KM Strategy within software engineering firms}

Software engineering knowledge is highly contextual, involving a significant amount of knowledge that is not possible to codify (Desouza, 2003; Lindvall \& Rus, 2002; Papadopoulos, et al., 2009). This knowledge can be considered as being highly tied to its authors, and so socialization processes (Nonaka \& Takeuchi, 1995) are a key requirement for successfully sharing this knowledge. This suggests that the personalization approach to $\mathrm{KM}$ in software engineering firms may offer better benefits than the codification strategy. However, the personalization strategy is not the most popular within software engineering firms (Desouza, 2003). Most software engineering firms' KMSs are supported by technologies that support codification, such as bug tracking systems and document management systems. Even though they provide real benefits, they have serious limitations (Desouza, 2003). One of the most significant limitations of pursuing the codification strategy within the software engineering field is that software engineers have to make a great effort to translate their tacit knowledge into explicit knowledge. However, as software engineering knowledge is so highly contextual, a solution for one scenario may not fit in another one. As a consequence, software engineers may feel that the cost of codification outweighs perceived benefits (Desouza, 2003). Therefore, it has been argued that software engineering firms should encourage knowledge sharing and knowledge creation through dialogue between their members (Desouza, 2003).

There are technologies that support the personalization strategy that may fit within software engineering contexts. Gupta and Sharma (2004) divide technologies that support KMS into seven categories: expert systems, groupware, document management systems, decision support systems, semantic networks, databases and simulation tools. This taxonomy was enhanced by Raman \& Jennex (2010) who added the categories social media and geographical based systems. This research focuses on KMS that are supported by social media based systems, in particular, social networking sites, which according to Michailova \& Gupta (2005) support the personalization strategy.

\subsection{Enterprise Social Network Sites}

Social network sites (SNS) belong to the social software category of KMS (Avram, 2006; Raman \& Jennex, 2010). Social software provides a platform for conversational interaction between people or groups, connects social networks regardless of distance, and provides social feedback (Avram, 2006). Researchers have stated that reputation and trust are crucial for interactions within SNS (Avram, 2006). However what really makes SNS unique is that "they enable users to articulate and make visible their social networks" (Ellison \& Boyd, 2007, p. 211). SNS can be categorized into two broad types: public social networking tools, like Facebook or MiGente, and Enterprise social networking (ESN), like Flowr or Yammer. ESNs are designed to support social networking in an enterprise context (Richter, Riemer, \& Brocke, 2011). It is important to differentiate these two types because people's behaviours within one site and the other are significantly different. Therefore, studies on one context are not fully applicable in the other context (Richter, et al., 2011; Riemer, et al., 2010). There are two sorts of ESN: intranet social networking platforms, which are technically the same as SNS but only accessible in the enterprise Intranet; and ESNs that use a public SNS; for example, using LinkedIn for recruiting (Richter, et al., 2011). For the purpose of this paper, we use the term ESN to refer only to intranet social networking platforms.

According to Miller, Marks, and DeCoulode (2011) ESNs' capabilities enable organizations to easily identify expertise and improve cross-boundary communication. For example, there are organizations that mainly use ESN as a medium for providing updates about activities and events to the rest of the organization (Riemer, et al., 2010); others use ESN as a mean for identifying experts and knowledge 
bearers, building personal context and fostering existing relationships (Richter \& Riemer, 2009). Still other companies have implemented the technology in order to enable users to connect with their colleagues in personal and professional way (DiMicco, et al., 2008). The evidence suggests that ESN has a variety of uses depending on the organizational context.

Individual motivations for using ESN at work are different depending on the individual. DiMicco, et al. (2008) identified three individual motivations: users use ESNs for promoting themselves and connecting strategically; for gathering support for their projects; and for keeping weak ties with colleagues. Ellison and Boyd (2007) found that people do not use ESNs for connecting people unless they have some kind of connection in the offline/real world.

ESNs are seen as having potential to support KMSs that pursue the personalization knowledge management strategy (Michailova \& Gupta, 2005). Nevertheless, significant different perceptions about the ESN might represent major barriers that may lead workers stopping using the ESN. For example, younger generations have very different practices to older generations surrounding the use of SNS. For instance, $48 \%$ of 18 to 34 year old Americans surveyed stated that they found out about news through a social networking tool; furthermore, about $28 \%$ of them reported checking their Facebook on their smart phones before getting out of bed (OnlineSchools.org, 2011). These kinds of practices have created a massive generational gap, compared only with the hippie movement in $70 \mathrm{~s}$, where older generations did not completely understand communication practices and beliefs of new generations (Dretzin \& Maggio, 2008). As a consequence, different age groups of people may have significant different assumptions, knowledge and expectations about ESNs. Not only generational differences, but also one's role and hierarchical position within the organization may be a source of different perceptions. For instance, due to the potential for ESNs to expose personal information (Begel, DeLine, \& Zimmermann, 2010), a manager could view an ESN as a useful tool for finding and connecting people with a knowledgeable and helpful colleague, while from the employee's point of view the ESN could seem to be corporate spyware (Begel, et al., 2010).

In order to help understand how divergent perceptions about ESNs may make the difference between a successful initiative and an unsuccessful one, we employ the TFR framework (Orlikowski and Gash, 1994) as a theoretical lens. We selected this framework because it has been widely used and has formed the basis for a genre of studies on processes related to IT in organizations (Davidson, 2006). The following section briefly explains this framework, which involves people's perceptions about technologies and the consequences of divergent perceptions between them.

\subsection{Technological Frames of Reference Framework}

Orlikowski \& Gash (1994) developed an analytical approach centred on the concept of technological frames to understand and explain how organization members make sense of information technologies and how their interpretations shape subsequent actions towards IT. Technological frames are defined as the "subset of members' organizational frames that concern the assumptions, expectations, and knowledge they use to understand technology in organizations" (Orlikowski \& Gash, 1994, p. 178). Technological frames not only refer to the technology itself, but also include local understanding of specific uses in a given setting. The authors propose three frames for understanding peoples' interpretations of a particular technology:

- Technology Strategy: People's views of why their organization acquired and implemented the technology. This includes their understanding of the motivation or vision behind the adoption decision and its likely value to the organization.

- Technology in use: People's understandings of how the technology will be used on a day-to-day basis and the likely or actual conditions and consequences associated with such use.

- Nature of technology: People's images of the technology and their understanding of its capabilities and functionality.

In practical terms, analysing stakeholder's technological frames may assist IS designers and implementers in bringing to the surface the incongruent technological frames. The notion of congruence in technological frames refers to the alignment of frames on key elements or categories, which does not mean they have to be identical, "but related in structure (i.e., common categories of 
frames) and content (i.e., similar values on the common categories)" (Orlikowski \& Gash, 1994, p. 180). Significant incongruence in the extent and nature of frames between different groups within an organization may lead to certain actions and/or inactions that may hamper the implementation of a new technology. Furthermore, incongruence may be difficult to change later when perceptions are formed through the initial exposure to the technology. Therefore, early identification of incongruence may help organizations avoid difficulties during IT implementations (Orlikowski \& Gash, 1994). When identifying incongruence, it is important to distinguish its nature. Incongruence might exist due to political differences or due to information deficiencies. Interventions for dealing with a particular incongruence should be different depending on its extent and nature (Orlikowski \& Gash, 1994). Although the three frames described above are considered to fit different technologies and contexts, Orlikowski and Gash suggest that they should be complemented with other frames in the case of a particular technology and/or context if this aids understanding.

Even though the TFR framework has been used in a large number studies using the, there are critics of the theory. Davison and Pai (2004) argue that merely becoming aware of divergent frames is not sufficient to improve either design or user acceptability, and that the framework lacks mechanisms to resolve issues relating to structural aspects of incongruence. Furthermore, they argue that the TFR framework tends to be used as a post hoc explanation of unsuccessful IS implementations. Therefore, the theory offers limited value to IS practitioners (Davison and Pai, 2004). However, Davidson (2006) presents suggestions about how to use the theoretical frames theory for practice, such as looking for incongruent frames before implementing the technology through, for example, surveys or focus groups, and aligning them.

\subsection{Summary}

The literature shows that implementations of ESNs have had mixed results and do not always result in organisational benefits. While this may be due to a combination of factors, several studies have revealed different assumptions and behaviours surrounding the use of SNSs by organizations. Studies using the TFR framework have previously shown that perceptions can play a key role in IS success and may lead to conflicts in using it (Orlikowski \& Gash, 1994), but there appear to be no studies employing the TFR framework lens to investigate the impact of perceptions about ESNs as part of a KMS. This study aimed to fill this gap and to identify what framing issues may arise in this context.

\section{RESEARCH METHOD}

Our study was guided by the overarching question, "how do the perceptions of different stakeholders affect the use of an enterprise social networking site as part of a knowledge management system within a software engineering firm?" This research used the structured case methodology. This is an iterative methodology that focuses on building theories from a systematic analysis of data collected; and comparing and contrasting outcomes with existing literature. We conducted four iterations: during the first iteration we conducted one key informant interview with an operational manager. During the second iteration two in-depth interviews were conducted with project life cycle managers. The third iteration involved conducting an in-depth interview with one C-Level Executive. The interviews were conducted in offices of the organization studied and one on Skype, for geographical reasons. All interviews were digitally recorded and transcribed. The interviewees had the opportunity to review the transcriptions before they were analysed. During the last iteration two focus groups were conducted, one with four software engineers and the other with four managers from different areas of the organization. In order to build a picture of overall participation that helped contextualize the interview and focus groups data, the ESN $\log$ files were also analyzed.

The case was an ESN implementation in an American software engineering firm with 1400 employees with operations in the Americas, Oceania, Africa, Asia and Europe. The pseudonym South Winds is used for the firm. South Winds has three R\&D centres geographically dispersed in different continents. South Winds' headquarters are located in the Silicon Valley, California, USA. They produce a suite of live systems made up of hardware and software. They compete in their market as innovators and provide some product and services to some niche markets. 
Participants were selected using purposive sampling. This selection was performed through different levels and departments of the organization aiming for a triangulation of subjects (Rubin \& Rubin, 2005). The twelve participants were organizational members from different organizational positions: $\mathrm{C}$-Level executives, operational managers, non-operational managers and software engineers. For the purpose of analysis, participants were grouped into three groups: C-Level, Middle Managers and Software Engineering staff.

For analysing the data, we used both inductive and deductive strategies. The inductive strategy was based on text analysis (Cresswell, 1994). Following an iterative and evolutionary process, we coded concepts, stories and themes. These codes were merged, revised and added to as we moved towards more abstract themes, based on our emerging understanding. We also compared codes within and between the groups of participants. We also used a deductive coding strategy based on the TFR framework outlined previously, coding data using the categorization technique described by Rubin and Rubin (1995). The entire process was assisted by NVivo 9 (qualitative analysis software).

While the study was based in the interpretive tradition, our reflection on the findings was also informed by the critical perspective and insights of the primary researcher who works as a software engineer in the company studied. We took several steps to improve the trustworthiness and credibility of results. Once the findings were consolidated from the concepts, they were verified through two strategies: return to data and participant check. The first strategy consisted of checking that the findings fitted with data collected through the focus groups and interviews; and also with logs collected through the ESN. The second strategy refers to checking findings with participants, which is useful to mitigate the researcher's subjectivity. Our findings were checked with one middle manager and one lead software engineer. Because of time limitations, it was not possible to check results with a C-Level representative.

\section{FINDINGS}

\subsection{Overview}

At the end of 2011 about twenty percent of the company had an account on the ESN tool. During the second half of 2011, there were 3542 successful logins into the platform, 305 posts (initial posts and answers) and 100 "Like This" interactions. We found that middle managers were the most active publishers, software engineers were mostly readers, and C-Level staff did not regularly use the ESN.

The middle managers group considered themselves as active publishers. They noted two main drivers for publishing: sharing knowledge and promoting projects that they led. They stated they proactively shared industry knowledge for the sake of teaching. For instance, one manager said: "I educated a few [people] by posting some stuff on [the ESN]. It's just to let everyone know". On the other hand, some managers posted information about the products for which they were leading developments. Their goal was to increase the knowledge about their projects across the organization and thereby create opportunities. This driver was explicitly supported by some executives. However, there was no specialized or dedicated human resource leading these initiatives. These drivers for using the ESN were consistent with other case studies found in the literature (DiMicco, et al., 2008). By contrast, software engineering staff described themselves as readers. In the focus group they stated that they did not regularly post using the tool ("I just read it"). Similarly, the C-Level group stated they did not actively post on the ESN. Although some level of monitoring was being performed by them, they conducted no internal communications within the tool.

We identified five categories (frames of reference) within which employees at South Winds held perceptions about the ESN. Three were from the Orlikowski and Gash's TFR framework (technology strategy, nature of technology, and technology in use), while the other two frames emerged from the inductive data analysis: personal technology success and technology adoption. The personal technology success frame refers to people's perceptions about how the ESN could provide success to them. The technology adoption frame refers to people's perception about the most suitable method for adoption and encouraging employees to use the ESN. 
Perceptions between the three organizational groups were found to be significantly divergent in four out of these five categories. Table 1 summarizes these divergences.

\begin{tabular}{|l|l|l|l|}
\hline & \multicolumn{1}{|c|}{ C-Level } & \multicolumn{1}{c|}{ Middle Managers } & \multicolumn{1}{c|}{ Staff } \\
\hline $\begin{array}{l}\text { Technology } \\
\text { Strategy }\end{array}$ & $\begin{array}{l}\text { To collect ideas from staff } \\
\text { and internally promote } \\
\text { projects }\end{array}$ & Largely Unknown & Largely Unknown \\
\hline $\begin{array}{l}\text { Nature of } \\
\text { Technology }\end{array}$ & $\begin{array}{l}\text { Lack of understanding of } \\
\text { the capabilities of the tool. } \\
\text { Concern about potential } \\
\text { knowledge leaking. }\end{array}$ & $\begin{array}{l}\text { Low level of understanding of } \\
\text { the nature of the technology. } \\
\text { They also perceived that the } \\
\text { tool deployment quality as } \\
\text { lower than was needed. }\end{array}$ & $\begin{array}{l}\text { Nature of the technology } \\
\text { not fully understood. They } \\
\text { also perceived that the tool } \\
\text { deployment quality as } \\
\text { lower than was needed. }\end{array}$ \\
\hline $\begin{array}{l}\text { Technology in } \\
\text { Use }\end{array}$ & $\begin{array}{l}\text { The ESN may lead to a } \\
\text { waste of productive time. }\end{array}$ & $\begin{array}{l}\text { Support to their projects. They } \\
\text { also perceive the ESN as a } \\
\text { means for sharing knowledge. }\end{array}$ & $\begin{array}{l}\text { Support for their ideas but } \\
\text { risk of hampering their } \\
\text { professional image. }\end{array}$ \\
\hline $\begin{array}{l}\text { Pechonal } \\
\text { Success }\end{array}$ & $\begin{array}{l}\text { It would be successful if } \\
\text { the technology enables the } \\
\text { organization to collect } \\
\text { ideas. }\end{array}$ & $\begin{array}{l}\text { It would be successful if the } \\
\text { entire organization would be } \\
\text { involved in sharing } \\
\text { knowledge. It would allow } \\
\text { them to internally promote } \\
\text { their products. }\end{array}$ & $\begin{array}{l}\text { It would be successful if } \\
\text { the ESN enabled them to } \\
\text { hear/talk from the top } \\
\text { management. Thereby, } \\
\text { they could promote their } \\
\text { ideas. }\end{array}$ \\
\hline $\begin{array}{l}\text { Technology } \\
\text { Adoption }\end{array}$ & $\begin{array}{l}\text { Ground-up approach. The } \\
\text { ESN should be allowed but } \\
\text { not promoted. }\end{array}$ & $\begin{array}{l}\text { The top-down approach was } \\
\text { largely preferred. }\end{array}$ & $\begin{array}{l}\text { The top-down approach } \\
\text { was largely preferred. }\end{array}$ \\
\hline
\end{tabular}

Table 1. Summary of the perceptions across South Winds

These divergences may explain the emergence of a social order that discouraged employees to create and share knowledge through the ESN and thereby precipitated the decision (after our data gathering was completed) to abort the ESN project. The only frame within which there was significant congruence between the perceptions of all three groups was personal technology success. Even though explaining why these perceptions were divergent is out of the scope of this research, it may be argued that a lack of a formal corporate communicational plan enabled the persistence of these divergences.

We now outline in detail the nature of the divergences and incongruencies in each frame category and examine the impact of these divergences on the use of the ESN as a part of South Winds' KMS.

\subsection{Discussion}

\subsubsection{Perceptions about Technology Strategy}

Although there was an incipient consensus about the usefulness of the technological artefact for collecting ideas, incongruent perceptions about the organizational strategy were found between the three groups. According to an executive, the organization had acquired an ESN in order to collect ideas from staff through a collaborative approach. This executive also saw the technology implementation as a means of helping the organization promote some products internally.

Hypothetically, it seems that an ESN could support this strategy because of its natural ability to break silos by enabling conversations between people or groups regardless of the distance (Avram, 2006). Following this reasoning, it seems that the C-Level executives' motivation behind the ESN adoption was aligned with the ESN's capabilities. However, six of the seven middle managers were not aware of the organizational strategy for adopting the ESN. As a consequence, they were not able to design processes for supporting this strategy. Similarly, three of the four software engineers were not aware of the motivations behind the ESN acquisition. However, they perceived the tool as an efficient channel for sharing their ideas with the top management. Nevertheless, they stated that they felt that their voices would not be listened to within the ESN. 
Considering that (1) middle managers were largely ignorant about the C-Level's motivations for acquiring the ESN, (2) software engineers were not posting because they perceived they would not have been listened to, and (3) ironically, the C-Level managers were monitoring posts on the ESN; it seems that the technology strategy incongruencies were due to information deficiencies despite the perceptions about power politics expressed by the engineers. Poorly aligned communication objectives for knowledge management initiatives have been previously indicated as failure predictors (Levett \& Guenov, 2000; Mohamed, et al., 2006).

\subsubsection{Perceptions about Nature of Technology}

There was some level of congruence in perceptions about the nature of technology between middle managers and software engineering staff. However, these congruent perceptions were largely misaligned with the actual nature of the technology. On the other hand, incongruence was found between organizational members with strong technical background (an executive, software engineers and technical middle managers) and organizational members with non-technical background. The first group perceived the technical ESN deployment as being extremely poor (reflecting their professional values), while the second group were pleased with the ESN deployment.

There was a widespread belief amongst middle managers and software engineer staff that a high level of employee's participation within the ESN was key for realizing benefits from adopting an ESN. However, employees stated they thought that people were not participating within the tool. One manager asserted: "it's just not [working]. Everyone is not just jumping in and publishing papers". As a consequence, a vicious cycle was created: employees were under the impression that nobody was using the tool, so they did not use the ESN. Nevertheless, it seemed that people had a fallacious assumption for assessing whether people were using or not the ESN. It seemed that this expectation arose from the lack of understanding of the participation inequality characteristic, which is part of the nature of online communities (Whittaker, Terveen, Hill, \& Cherny, 1998). Participation inequality refers to the unequal participation distribution between online communities' members. This user participation follows a Zipf distribution. This can be explained with the 90-9-1 rule (Nielsen, 2006). This rule means that $90 \%$ of users are readers and they do not contribute. $9 \%$ of users barely contribute, but it is not their priority. Only $1 \%$ are active contributors. This $90-9-1$ rule is only a figure for explaining the Zipf distribution. From the analysis of the South Winds ESN's logs, it was found that the distribution of posting at South Winds followed this Zipf pattern exactly.

Another congruent perception among the software engineer group and the middle managers group was the impression that the ESN's core capability was storing knowledge. This was expressed in recurrent references to the ESN being a competitor of a Wiki: "there are already competing tools out there that people prefer over Flowr like the wiki". This perception was mainly captured from the middle managers group and to a lesser degree in the software engineers group: "The format of Flowr limits the content. [...] If you compare Flowr with our Wiki, a Wiki contain a lot of more information than Flowr in term of details". Given that an ESN is a social software providing a platform for conversational interaction between people or groups (Avram, 2006), while a Wiki is essentially a collection of Web sites connected via hyperlinks where users can modify content via a web browser, it appears that there were misconceptions of the nature of the ESN as a tool. As a consequence of this misconception, managers were ignoring the ESN because they felt their knowledge needs were covered by the Wiki.

Software engineers' perception about the nature of the technology was related to the quality of the ESN deployment. From the technical perspective, technical background staff stated they thought that the ESN's quality was lower than the acceptable levels. One software designer said: "another problem of the ESN is that it's quite flaky [slang for unreliable]". By contrast, non-technical staffs were pleased with the ESN deployment. It is important to highlight that the engineers were not only referring to the ESN itself, but also to the tool's deployment within the IT infrastructure. 


\subsubsection{Perceptions about Technology in Use}

A congruent perception about the potential positive impact of using the ESN for promoting projects was found across all the groups. However, incongruent perceptions about the consequences of using the ESN were found. There was a significant concern among executives of potential productivity losses because of using the ESN, which may partially explained why they did not promote it (this point will be deeply discussed in the "perceptions about technology adoption" section).

The last thing we want to do is to bring Facebook syndrome into work. [...] That would be a worst case scenario. Don't get anything done but you talking about what you planning to do. A nightmare. It's all about distraction

Prior evidence suggests that this risk did not represent a real threat because people do not tend to use ENSs for leisure like they do in public social networking sites (Riemer, et al., 2010). Furthermore, studies have shown that employees may use ESNs in a productive way (Riemer, et al., 2010). In addition, South Winds' software engineering staff stated that they would not have used the ESN for leisure purposes because they perceived that doing so may hamper their professional image: "I would not post something on the public stream unless I talk very carefully about it".

Software engineering staff stated they were concerned about how their professional image might be affected from using an ESN. Furthermore, a few studies show similarities between the impression management strategies deployed on public social networking sites and in offline life (Buffardi \& Campbell, 2008; Donath \& Boyd, 2004; Gosling, Gaddis, \& Vazire, 2007). Impression management refers to people's strategies for influencing the impressions others hold about them (Goffman, 1959). Due to ESNs being a medium that reveals user's knowledge, expertise, activities or availability (Begel, et al., 2010), it appears that impression management may play a key role in determining people's behaviours within ESNs. The influence of impression management suggests that: (1) CExecutive perceptions about losing productivity because of using an ESN were baseless, and (2) a ground-up adoption approach was not the most suitable approach for an ESN. (This is discussed in the perceptions about technology adoption section).

Middle managers and software engineering staff perceived that using the ESN would allow them to promote their projects and ideas respectively: "if I have an idea or problem that the CEO could support". Moreover, middle managers stated that the ESN would allow them to break silos and thereby transfer knowledge that people from other teams may need to better perform their tasks: "[the ESN] appeals to me because it could cut across several groups". Furthermore, executives supported using the ESN with this end. However, a significant incongruent perception generated conflicts in using the ESN for systematically sharing knowledge: while the executives considered that the level of penetration was not a decisive factor for realizing benefits from the ESN, the rest of the organization considered that that it was essential to get the whole corporation involved in using the ESN.

\subsubsection{Perceptions about Personal Technology Success}

Perceptions about personal technology success were in some extent congruent across the different levels of the organization. The C-Level managers stated that they would consider the ESN implementation as a success if the ESN supported their strategy for acquiring the technology: generating/sharing knowledge or, in their words, collecting ideas from staff and internally promoting projects. An executive stated: "the company would get some benefits [...] come up with some good ideas". He also stated: "I think [promoting products and technologies through the ESN] is a very good example of how this tool could help us". In this case there was congruence between the technology strategy and personal technology success frames. This may be because this C-Executive was championing the initiative. However, personal technology success is a valuable frame to consider because of the potential for misalignment.

Middle managers stated that they would consider the ESN's implementation as a success if the tool enabled them to promote their projects across different organizational groups. This may explain why they also expected that the ESN should have been widely used across the entire organization. 
There are lost opportunities. You don't know what you don't know. If you don't know you have a product with a certain capability and you find yourself in a sales situation with a customer, let's say you are an account manager or a sales guy, how can you best sell that product to that customer if you don't know aspects about the product?.[...] I think this tool can assist that.

Finally, software engineering staff perceived that the ESN would be a success if it allowed them to share their ideas about product or to highlight organizational tacit problems. One of them said: "if you have an idea and it could get the CEO, when it is very unlikely that you copy [in an email] the CEO". Even though there was a high level of congruence within this frame, the ESN was largely perceived as an unsuccessful IS deployment.

\subsubsection{Perceptions about Technology Adoption}

Incongruent perceptions between different groups were found in regard to the adoption approach that should have been used by South Winds. The C-Level group perceived that the suitable model for adopting the ESN was a ground-up approach. In the ground-up approach, neither promotion, processes nor rewarding schema are applied from higher levels. This was the approach being undertaken at the time the study was performed. However, middle managers and software engineers did not share this perception. One middle manager said:

The gap [for realizing the potential benefits] is for someone in ability in the company to pick up the [tool]... Someone who could say: 'ok, how could make it work for YOU guys?'. Then you make customizations for me, changing company process, all the rules and regulations.

It seemed that perceptions about technology adoption were strongly influenced by perceptions about the technology in use and nature of the technology. In South Winds, the decision of using a ground-up approach for using the ESN was taken by the C-Level executives: "I would say [the ESN] is allowed, [it is like] Skype it's not promoted it's allowed". However, this approach discouraged knowledge creation/sharing within South Winds through the ESN because of two inherent elements of ESNs, impression management and participation inequality.

The knowledge markets theory (Davenport \& Prusak, 2000) can be used to cast light on the impact of the adoption approach on the usage of the ESN considering these elements (i.e., impression management and participation inequality). A knowledge market is an abstraction to understand how knowledge is exchanged. It is possible to identify at least two roles: knowledge buyers and knowledge sellers (Davenport \& Prusak, 2000). Knowledge buyers are individuals who are looking for knowledge in order to solve a problem that its complexity exceeds its own knowledge. Within an organization everyone is a buyer but not everyone can be a seller. Knowledge sellers are people with an internal market reputation for having knowledge about a particular matter. Assuming that knowledge is power, knowledge owners may not want to share their knowledge because this may dissipate their power (Davenport \& Prusak, 2000).

The decision for using a ground-up approach in South Winds was challenged by the ESN's effect on people's impression management. People seek to become a knowledge seller in order to gain organizational power (Davenport \& Prusak, 2000). In order to become a knowledge seller, one must be internally known as a knowledgeable person. Then, exposing oneself in an open communication channel like an ESN might dissipate their knowledgeable reputation because when ESNs' users post in the public stream, they are talking to the entire organization. Then, they do not only talk to people with whom they hold static relationships, but they also talk to people with whom they hold weak ties where reputation may have not been developed. By contrast, most of the SNSs open a communication channel between people that mutually agree to belong to the same online social circle, where their activities are constrained. Hence, within the ESN context it is unlikely that people voluntarily assume costs without foreseen any potential benefit. This suggests that a top-down approach would have been needed in South Winds in order to either decrease the perceived costs of sharing knowledge or include a reward schema to increase the perception that potential benefits may overweigh the costs of being exposed. 
The second aspect that challenged the decision for using a ground-up approach within South Winds was participation inequality. There was a widely spread belief within South Winds that the ESN was not being used because people were not massively sharing their knowledge. This is an unrealistic expectation because, as was discussed earlier, participation inequality is an inherent aspect of ESNs. Following the analysis through the knowledge market theory lens, this expectation made people perceive that nobody was buying knowledge. In other words, the ground-up approach developed an anomalous knowledge market system price. Within internal knowledge market theory, the knowledge is exchanged for three "currencies": reciprocity, repute and altruism (Davenport \& Prusak, 2000). Reciprocity is the currency for knowledge transactions that are based on the seller's belief that the buyer will act as a seller in the future. Reputation is the currency used when the seller wants others to know him as a knowledgeable person with valuable expertise. And altruism appears when sellers do not want any reward for sharing their knowledge. This case can rarely be seen in, for example, mentoring relationships (Davenport \& Prusak, 2000). These intangible currencies can eventually become tangible rewards through, for example, performance reviews. Within South Winds, the ground-up approach had produced a lack of interest in selling knowledge through the ESN, because there was nobody formally paying for the knowledge. This could be seen in two employees' practices: (1) they did not help others through the ESN. This may have been because they did not perceive any potential reciprocity in helping others ("When you read someone else's post, I don't reply. [I think] this it not really for me or I wait for an active user to respond"); and (2) they did not share their knowledge because they perceived that publishing within the ESN may hamper their reputation. In other words, they perceived that the cost of posting on the ESN overweighed the potential benefits in doing it.

\section{DISCUSSION AND IMPLICATIONS}

Even though this research used one in-depth case study, we believe the results of this research are of broader value. From the interpretive position, the validity of extrapolation relies "on the plausibility and cogency of the logical reasoning used in describing the results from the cases and in drawing conclusions from them" (Walsham, 1993, p. 15). This differs from traditions such as positivism in which the validity of an extrapolation depends on the representativeness of the cases in a statistical sense. Furthermore, a single case study may provide richness of understanding of a problem, which is particularly appropriate for those problems in which research and theory are at their early formative stages (Benbasat, Goldstein \& Mead, 1987), as was the case with the problem studied.

The findings outlined above suggest that there may be value in adding two extra technological frames of reference in studies of technology implementation: Personal Technology Success and Technology Adoption. Even though our study investigated the use of ESNs as a part of a KMS, the frames may have broader applicability. The Personal Technology Success frame refers to people's perceptions about how an information system would be perceived to be successful to them within a given context. The existence of this frame became clear from statements made during the interviews and focus groups. To use this frame implies believing that an information success is a matter of interpretation. Thus, congruent perceptions about Personal Technology Success would be needed for the whole organization to consider the information system as a success. Furthermore, understanding people's perceptions about Personal Technology Success may reveal potential political resistances. Divergent perceptions about Personal Technology Success and perceptions about Technological Strategy among organizational members may be a predictor of negative political attitudes towards the IS. This is because organizational motivations behind the IS (Technology Strategy) might be, for example, perceived as a threat for individuals.

The Technology Adoption frame refers to people's perception about what is the suitable method for encouraging employees using an information system. Applying this frame to the knowledge management systems domain would assist by revealing perceptions about the suitability of management intervention in relationship to employee's participation (whether a top-down or bottomup approach is considered suitable). The importance of understanding these perceptions may impact on the knowledge market system price. 
Our analysis also suggests that certain perceptions about a particular aspect of a technology may become the foundations for building perceptions about other aspects of the technology. From analysis of the South Winds' case study, a set of interrelationships between the technological frames emerged. Figure 1 presents a theoretical model of these frame interrelationships. The model assumes that knowledge is transacted within knowledge markets. The ovals represent the frames and the continuous arrows show the impact of frames on the construction of other frames or on the use of the technology. The dotted arrow shows an impact that is proportional to the power held by the individual. This shows the value of the alignment of perceptions between non-powerful and powerful individuals. The model requires exploration and confirmation through further research.

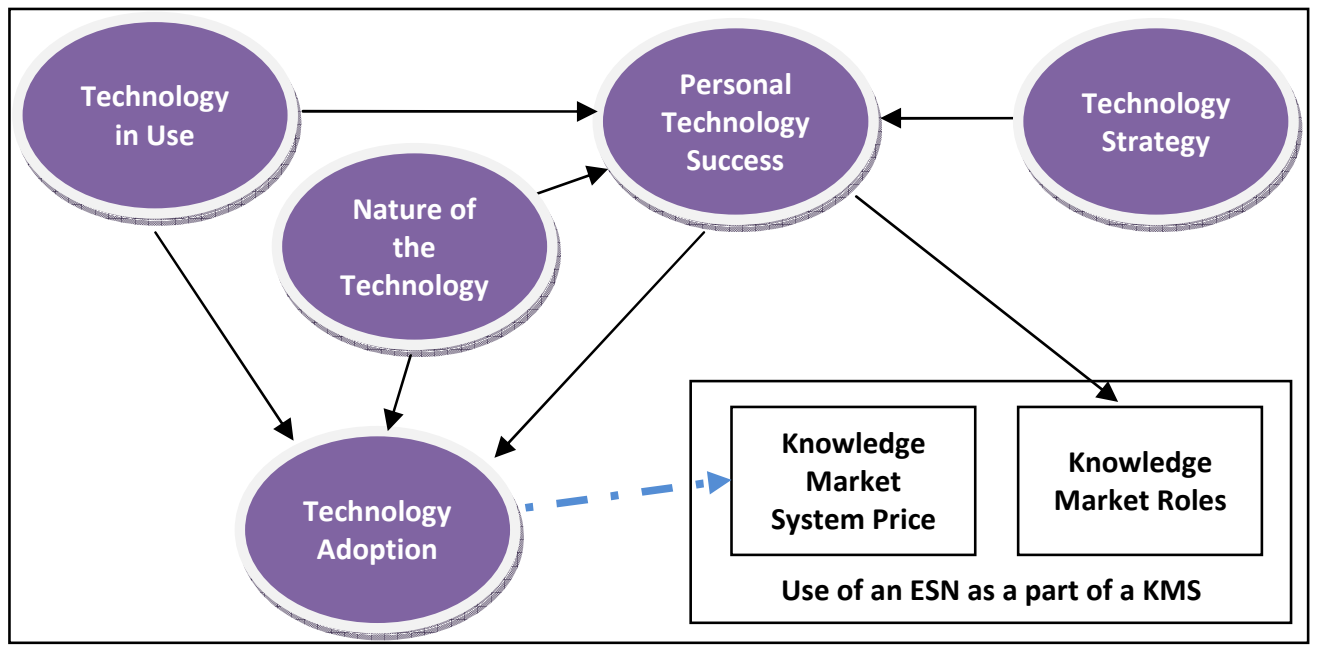

Figure 1. Theoretical view of the impacts of the people's perceptions about the ESN

It was found that the perceptions of South Winds' employees about Technology Strategy; Technology in Use; and Nature of the Technology impacted on their perceptions about personal technology success. This implies that perceptions about the organizational motivations behind implementing the technology may be aligned with perceptions about personal technology success. For instance, it was found in the South Winds case study that middle managers were unaware of the technology strategy; however, they built their perceptions based on their perceptions about the consequences of using the ESN (technology in use) and the ESN's technical capabilities (nature of the technology). On the other hand, the C-Level managers built their perceptions about personal technology success mainly based on their perceptions about the technology strategy, because they largely lacked understanding about the nature of the technological artefact.

Perceptions about the Nature of the Technology, Technology in use and Personal Technology Success directly affect people's perceptions about technology adoption. This means that lacking knowledge about the actual capabilities and potential consequences of the technological artefact; and/or misaligned perceptions about personal success criteria with technology strategy may foster the development of dysfunctional perceptions about what is a suitable approach for technology adoption. However, we suggest that the level of impact of perceptions about technology adoption varies proportionally to the power held by the individual. For example, in the South Winds case study, most of the employees stated that the suitable approach for adopting the ESN was a top-down approach. Nevertheless, a ground-up approach was used. This was because the most powerful individuals perceived the ground-up approach as being suitable.

It was found that perceptions about Personal Technology Success impact on the role that individuals play in the knowledge market. For example, in the South Winds' case study, software engineers stated that they would have perceived the ESN implementation as a success if the tool had allowed them to promote their ideas and thereby gain support from higher levels. These perceptions would have led software engineers to act as knowledge sellers. On the other hand, some middle managers stated that they would have considered the ESN as a success if it had allowed them "to listen" to people who 
interact with customers in order to get feedback about the product for which they were leading development. These perceptions would have led them to act as knowledge buyers.

This theoretical model highlights the importance of effectively communicating the technology strategy, because of the technology strategy frame's role in building perceptions about personal technology success. It also highlights the relevance of fully understanding the actual capabilities and consequences of using the technology, particularly from powerful individuals, because of the impact on perceptions about technology adoption. This model also shows the value of the alignment of perceptions between the organization in order to avoid difficulties and conflicts around the use of the technology.

\section{SUMMARY AND CONCLUSION}

This research investigated how the perceptions of people in different roles impacted on the use of an ESN as a part of a knowledge management system within a software engineering firm. It found that C-Level executives, middle managers and software engineers held incongruent perceptions about the new technology and that these perceptions impacted on use. These perceptions occurred within five different frames about technology - three frames identified by Orlikowski and Gash (1994), technology strategy, nature of the technology and technology in use and two further frames identified in this study - technology adoption and personal technology success. It was found that incongruent perceptions were mainly due to information deficiencies rather than political reasons.

This research suggests that there is value in adding two extra technological frames of reference in studies of technology implementation: personal technology success and technology adoption. Even though our study investigated the use of ESN with a KMS, these frames may have broader applicability. Personal technology success refers to people's perceptions about how an information system would be perceived to be successful to them within a given context. Technology adoption refers to people's perception about the most suitable method for encouraging employees to use an information system.

This research also suggests that certain perceptions about a particular aspect of a technology can become the foundations for building perceptions about other aspects of the technology. A theoretical model of these frame interrelationships was presented. This model suggests that people assume different roles depending on the perceptions about personal technology success, which are built based on other perceptions. The model highlights the importance of (1) aligning perceptions about the technology across the organization, (2) getting understanding of the actual consequences of using and ESN, and (3) effectively communicating the technology strategy. Achieving these factors may lead an organization to create functional knowledge markets that encourage people to create and share knowledge through the technology. Nevertheless, the model is provisional and requires exploration and confirmation through further research. 


\section{References}

Alavi, M., \& Leidner, D. E. (1999). Knowledge management systems: issues, challenges, and benefits. Communications of the AIS, 1(2es), 1-es.

Alavi, M., \& Leidner, D. E. (2001). Review: Knowledge management and knowledge management systems: Conceptual foundations and research issues. MIS quarterly, 107-136.

Avram, G. (2006). At the crossroads of knowledge management and social software. Electronic Journal of Knowledge Management, 4(1), 1-10.

Baltatzis, G., Ormrod, D. G., \& Grainger, N. (2009). Social networking tools for internal communication in large organizations: benefits and barriers. Paper presented at the 19th Australasian Conference on Information Systems, Christchurch.

Begel, A., DeLine, R., \& Zimmermann, T. (2010). Social media for software engineering. Paper presented at the Proceedings of the FSE/SDP workshop on Future of software engineering research.

Benbasat, I., Goldstein, D. K., \& Mead, M. (1987). The Case Research Strategy in Studies of Information Systems. MIS quarterly, 11(3), 369-386.

Borchers, G. (2003). The software engineering impacts of cultural factors on multi-cultural software development teams.

Buffardi, L. E., \& Campbell, W. K. (2008). Narcissism and social networking web sites. Personality and social psychology bulletin, 34(10), 1303-1314.

Cresswell, J. (1994). Research Design: Qualitative and Quantitative Approaches. Thousand Oaks, CA: Sage.

Davenport, T., \& Prusak, L. (2000). Working knowledge: How organizations manage what they know: Harvard Business Press.

Davidson, C., \& Voss, P. (2002). Knowledge management: An introduction to creating competitive advantage from intellectual capital. Auckland: Tandem Press.

Davidson, E. (2006). A technological frames perspective on information technology and organizational change. The Journal of Applied Behavioral Science, 42(1), 23-39.

Davidson, E., Pai, D., Kaplan, B., Truex, D., Wastell, D., Wood-Harper, A., et al. (2004). Making Sense of Technological Frames: Promise, Progress, and Potential

Information Systems Research (Vol. 143, pp. 473-491): Springer Boston.

Desouza, K. (2003). Barriers to effective use of knowledge management systems in software engineering. Communications of the ACM, 46(1), 101.

DiMicco, J., Millen, D. R., Geyer, W., Dugan, C., Brownholtz, B., \& Muller, M. (2008). Motivations for social networking at work.

Donath, J., \& Boyd, D. (2004). Public displays of connection. BT Technology Journal, 22(4), 71-82.

Dretzin, R., \& Maggio, J. (Director) (2008). Growing Up Online. In D. Fanning (Producer). USA: Frontline.

Ellison, N. B., \& Boyd, D. (2007). Social network sites: Definition, history, and scholarship. Journal of Computer-Mediated Communication, 13(1), 210-230.

Gartner (2010). Gartner Reveals Five Social Software Predictions for 2010 and Beyond Retrieved 1502-2012, from http://www.gartner.com/it/page.jsp?id=1293114

Goffman, E. (1959). The presentation of self in everyday life. New York: Anchor.

Gosling, S. D., Gaddis, S., \& Vazire, S. (2007). Personality impressions based on Facebook profiles. Psychology, 1-4.

Greiner, M. E., Bohmann, T., \& Krcmar, H. (2007). A strategy for knowledge management. Journal of Knowledge Management, 11(6), 3-15.

Gupta, J. N. D., \& Sharma, S. K. (2004). Creating knowledge based organizations. Hershey, PA: Idea Group Publishing.

Hennink, M. M., Hutter, I., \& Bailey, A. (2011). Qualitative research methods: Sage.

Levett, G., \& Guenov, M. (2000). A methodology for knowledge management implementation. Journal of Knowledge Management, 4(3), 258-270.

Levy, M. (2009). WEB 2.0 implications on knowledge management. Journal of Knowledge Management, 13(1), 120-134. 
Lindvall, M., \& Rus, I. (2002). Knowledge management in software engineering. IEEE Software, 19(3), 26-38.

Michailova, S., \& Gupta, A. (2005). Knowledge sharing in consulting companies: Opportunities and limitations of knowledge codification. Journal of Information and Knowledge Management, 4(3), 201.

Miller, M., Marks, A., \& DeCoulode, M. (2011). Social Software for business performance. The missing link in social software: Measurable business performance improvements.: Deloitte.

Mohamed, M., Stankosky, M., \& Murray, A. (2006). Knowledge management and information technology: can they work in perfect harmony? Journal of Knowledge Management, 10(3), 103-116.

Morten, T., Nohria, N., \& Tierney, T. (1999). What's your strategy for managing knowledge. Harvard Business Review, 77(2), 106-116.

Myers, M. D. (1995). Dialectical hermeneutics: a theoretical framework for the implementation of information systems. Information Systems Journal, 5(1), 51-70.

Nielsen, J. (2006). Participation Inequality: Encouraging More Users to Participate Retrieved 11/12/2011, from http://www.useit.com/alertbox/participation_inequality.html

Nonaka, I., \& Takeuchi, H. (1995). The knowledge-creating company /Ikujiro Nonaka and Hiro Takeuchi. New York :: Oxford University Press.

OnlineSchools.org (2011). Obsessed with Facebook Retrieved 06/02/2011, from http://www.onlineschools.org/blog/facebook-obsession/

Orlikowski, W. J., \& Gash, D. C. (1994). Technological frames: making sense of information technology in organizations. ACM Transactions on Information Systems (TOIS), 12(2), 174207.

Papadopoulos, G. A., Wojtkowski, W., Wojtkowski, G., Wrycza, S., Zupancic, J. e., \& Damaševičius, R. (2009). On The Human, Organizational, and Technical Aspects of Software Development and Analysis Information Systems Development (pp. 11-19): Springer US.

Raman, M., \& Jennex, M. (2010). Knowledge Management Systems for Emergency Preparedness: The Way Forward. Journal of Information Technology Case and Application Research, 12(3), 10.

Richter, A., \& Riemer, K. (2009, December 2009). Corporate Social Networking Site - Modes of Use and Appropriation through Co-Evolution. Paper presented at the 20th Australasian Conference on Information Systems.

Richter, D., Riemer, K., \& Brocke, J. v. (2011). Internet Social Networking: Research State of the Art and Implications for Enterprise 2.0 (State of the Art). Business \& Information Systems Engineering.

Riemer, K., Richter, A., \& Seltsikas, P. (2010). Enterprise Microblogging: Procrastination or productive use? AMCIS 2010 Proceedings, 506.

Rubin, H. J., \& Rubin, I. (2005). Qualitative interviewing: The art of hearing data: Sage Publications, Inc.

Rubin, H. J., \& Rubin, I. S. (1995). Qualitative Interviewing. Thousands Oaks, CA: Sage.

Steinfield, C., DiMicco, J. M., Ellison, N. B., \& Lampe, C. (2009). Bowling online: social networking and social capital within the organization.

Strauss, A., \& Corbin, J. M. (1990). Basics of qualitative research: Grounded theory procedures and techniques: Sage Publications, Inc.

Walsham, G. (1993). Interpreting information systems in organizations. Chichester: Wiley

Whittaker, S., Terveen, L., Hill, W., \& Cherny, L. (1998). The dynamics of mass interaction. Paper presented at the Proceedings of CSCW 98, the ACM Conference on Computer-Supported Cooperative Work, (Seattle, WA, November 14-18, 1998).

Wiig, K. M. (1997). Knowledge Management: An Introduction and Perspective. Journal of Knowledge Management, 1(1), 9. 